\title{
siso \\ Guardianes del paraíso. Génesis y genealogía de una identidad colectiva en Mar de las Pampas, Provincia de Buenos Aires
}

RMA

Antropología Social

\author{
Gabriel David Noel
}

CONICET, Instituto de Altos Estudios Sociales, Universidad Nacional de San

Martín. E-mail: gdnoel@gmail.com

\begin{abstract}
Resumen
La localidad balnearia de Mar de las Pampas (Buenos Aires, Argentina) ha experimentado en la última década un proceso inédito de expansión de su infraestructura edilicia y de servicios dirigidos al turismo. Al mismo tiempo, la inmensa mayoría de sus residentes permanentes perciben este crecimiento como una amenaza a su proyecto de construcción colectiva de una comunidad "virtuosa" argumentada en torno de valores como la "ecología", lo "natural" y la "calidad de vida".

Nuestro texto busca mostrar algunas de las formas en que los residentes permanentes plantean y responden las preguntas acerca de qué es, qué debe ser y qué no Mar de las Pampas - así como los repertorios morales a los que los mismos recurren - en el marco de una narrativa moral que opone un proyecto "virtuoso" y "auténtico" de "comunidad" a los intereses "espurios" de una "especulación inmobiliaria" y un "progreso desenfrenado" que buscarían corromper el proyecto de estos "vecinos", así como la manera en la cual estas disputas contribuyen a la consolidación de una identidad colectiva compartida para sus pobladores.
\end{abstract}

Palabras Clave: identidad colectiva; moralidades; construcción de comunidad; ecologismo; localidades turísticas.

Guardians of Paradise. Genesis and genealogy of a collective identity in Mar de las Pampas, Buenos Aires Province

\begin{abstract}
Mar de las Pampas, a seaside resort on the Atlantic Seaboard of the province of Buenos Aires (Argentina) has undergone in the last decade a process of massive expansion of its touristic infrastructure (especially on lodging and commercial facilities). At the same time, most of its full-time residents consider this process as a threat looming over their own project of collective construction of a virtuous community, grounded in values such as "ecology", "natural life" and "quality of life".

Our text will attempt to show some of the ways in which the permanent residents of Mar de las Pampas pose and answer their questions about what Mar de las Pampas is, what should it be and what should it strive not to be, as well as the moral repertoires on which they are grounded, in the context of a moral narrative that opposes a "virtuous" and "authentic" community to the spurious interests of "voracious realtors" engaged in "acts of speculation" that seek to corrupt the former. At the same time we will show these disputes contribute to the consolidation of a shared collective identity among its dwellers.
\end{abstract}

Keywords: collective identity; moralities; community-building; environmentalism; touristic resorts.

A comienzos del año 2003 y sobre el fondo de un relativo anonimato, la localidad balnearia de Mar de las Pampas, localizada en el partido de Villa Gesell, unos $420 \mathrm{Km}$. al sur de la ciudad de Buenos Aires, comienza a ser mencionada con cierta insistencia en los medios de prensa de alcance nacional.

Lo inusual del caso es que estas menciones no se detienen en los habituales lugares comunes del "sol y playa" sino que se ocupan de un proceso de crecimiento - edilicio sobre todo, pero también laboral y económico - cuya magnitud y velocidad pareciera requerir del abuso de la hipérbole. A modo de ejemplo podemos citar una nota publicada en el matutino La Nación, el 22 de septiembre de 2003 y que lleva por título "Sorprendente boom inmobiliario en Mar de las Pampas":

"Abundan los emprendimientos privados y el trabajo. Bosques y arena se convirtieron de repente en un gran obrador. Las dunas compiten en altura con las montañas de ladrillos y bolsas de cemento. Casas, cabañas y aparts en los que predominan piedras y troncos dibujan la nueva

Recibido 29-04-2011. Recibido con correcciones 29-09-2011. Aceptado 31-10-2011 
y coqueta escenografía de este balneario que desde hace poco más de veinte meses vive una verdadera explosión inmobiliaria.

(...) en lo que va de este año se pusieron en marcha 234 obras. Es decir que cada día se rellenan los cimientos para una nueva propiedad (...)"1

Aunque a casi una década de distancia el énfasis y el tono de sorpresa puedan aparecer impostados, no debemos olvidar que nos encontramos en 2003, y que el ciclo recesivo comenzado a mediados de los 90 y que encontrara su resolución explosiva en los hechos de diciembre de $2001^{2}$ está aún demasiado presente en la memoria colectiva de los argentinos ${ }^{3}$. Sólo así - luego de casi diez años de depresión económica y una tasa abierta de desempleo que en varias ocasiones rebasó el 20\% puede explicarse la insistencia entusiasta y elogiosa en la abundancia de emprendimientos, la magnitud de la demanda y la generosa oferta laboral o que el redactor se sienta tentado a subrayar a destacar el testimonio de una fuente que señala que "'Los valores están igual o por encima de los de la época de la convertibilidad""4.

A lo largo de los meses sucesivos, otros matutinos porteños comenzarán a replicar las menciones a este auge. Así, en los clasificados del diario Clarín del 29 de Diciembre de 2003, encontramos un destacado que lleva por título "Boom en Zonas Turísticas" 5 y que reproduce

\footnotetext{
1 Diario La Nación, "Sorprendente boom inmobiliario en Mar de las Pampas", 22 de septiembre de 2003.

2 "La crisis de 2001" o "Diciembre de 2001" hace referencia en Argentina a una serie de eventos que configuraron la mayor crisis institucional, política, social y económica de las últimas décadas, y que representaron la eclosión de las contradicciones implícitas en una década de políticas neoliberales inspiradas en el denominado "Consenso de Washington".

3 Sobre el papel de ciertos "hechos traumáticos" del campo político y económico en la construcción de la subjetividad, véase Grimson (2002).

4 La Ley de Convertibilidad o "1 a 1" fue una ley sancionada el 27 de Marzo de 1991, bajo los auspicios del entonces Ministro de Economía de Carlos S. Menem, Domingo Cavallo, en un intento de detener el proceso hiperinflacionario iniciado en 1989. La ley estipulaba una paridad cambiaria fija entre el peso argentino y el dólar estadounidense, para lo cual exigía la existencia de respaldo en reservas para el circulante en pesos. Si bien la convertibilidad consiguió su efecto inmediato y trajo una relativa prosperidad a los sectores medios y medio altos, sus efectos en el mediano y largo plazo fueron ruinosos para la economía argentina, y causa inmediata de la "crisis de 2001" ya mencionada. Durante los 11 años en los que la ley estuvo vigencia el apoyo de los sectores medios y altos a la política del 1 a 1 fue cuasiunánime, al punto de que la misma impuso límites a todas las propuestas electorales entre 1995 y 1999, incluso las de oposición, que debieron comprometerse a su sostenimiento como condición sine qua non de sustentabilidad política. Si bien actualmente existe un relativo consenso respecto de los efectos deletéreos de la convertibilidad, la situación no era tan clara ni tan unánime en 2003 (Semán 2006), al punto de que el ex-presidente Menem, responsable último por la política de la convertibilidad, obtendrá el primer lugar en la primera vuelta de las elecciones presidenciales de Abril, con casi el $25 \%$ de los votos.

${ }^{5}$ Diario Clarín, Clasificados, sección "Inmuebles", 29 de diciembre de
} 2003 la perplejidad ante una zona que "hizo algo más que sobrevivir a la crisis de 2001: duplicó el valor de los lotes en dólares". Pocos meses después, el suplemento de Arquitectura del mismo diario menciona Mar de las Pampas entre "las ciudades que más crecen", destacando la duplicación de su superficie construida en el último año ${ }^{6}$. El tercer matutino de cierta importancia, Página/12, titula "Explosión en las Pampas" su nota del domingo 4 de enero de 2004, y en su bajada recurre una vez más al gastado sintagma del "crecimiento explosivo"7 continuando con una tendencia que habrá de prolongarse en una serie de notas similares que aparecerán con cierta regularidad en los matutinos mencionados a lo largo de los siguientes años.

Sin embargo, este coro optimista de contratistas y emprendedores inmobiliarios, funcionarios locales, propietarios de complejos turísticos y comerciales y periodistas fascinados ante el espectáculo del crecimiento acelerado donde hace poco no había más que recesión y estancamiento, encuentra con frecuencia un contrapunto, que habrá de cobrar protagonismo creciente a medida que el proceso de expansión se prolongue y consolide. Este contrapunto aparece encarnado en los temores y reparos de una serie de "vecinos históricos" comerciantes menudos, emprendedores de pequeña escala y otros residentes permanentes cuyo arraigo antedata al comienzo del proceso de crecimiento ${ }^{8}-a$ quienes parece preocuparle que el proceso de expansión de la infraestructura (y en particular de la infraestructura turística $\left.{ }^{9}\right)$ arrase con ciertas peculiaridades que ellos

\footnotetext{
6 Diario Clarín, Suplemento Arquitectura "Investigación: las ciudades que más crecen", 12 de abril de 2004.

7 Diario Página/12, "La explosión de las pampas", 4 de diciembre de 2004.

8 En este sentido, no es casual que en la presentación de estos "vecinos", tanto en las notas periodísticas ya mencionadas como en la prensa local a la que tendremos ocasión de referirnos en breve, su nombre sea inmediatamente acompañado de la longitud de su arraigo, en la medida en que esta suele ser una referencia crucial a la hora de argumentar la legitimidad de sus reclamos.

${ }^{9}$ Cabe señalar que esta expansión tiene lugar en el marco de de lo que algunos autores denominan "neoexclusivismo" (Hernández 2009a, 2009b), proceso que estaría caracterizado por el surgimiento de un nuevo nicho comercial y de servicios destinado a los sectores altos y medio-altos y que intentaría reproducir, en clave turística, los procesos de suburbanización que atravesaron a estos sectores socialmente móviles durante las últimas décadas (Svampa 2001). Quisiéramos señalar que aunque en líneas generales pueda reconocerse la existencia de un proceso "neoexclusivista" como el postulado por el autor citados, creemos que su caracterización del mismo adolece de un exceso de imputación analítica. Tal como el autor lo presenta, este "neoexclusivismo" aparece como una estrategia de mercado "impuesta desde arriba" de manera unilateral y monolítica. Sin embargo, la realidad empírica se muestra más compleja: si bien se multiplican una suerte de "estéticas de lo verde" y de "lo lindo" que forman parte de un nuevo modelo de comercialización de la propiedad inmueble en la costa bonaerense, no debemos olvidar - como nos ha enseñado entre otros Herzfeld (2003) - que símbolos formalmente idénticos pueden ser movilizados en sentidos divergentes, o incluso opuestos. Como veremos, nuestros informantes de Mar de las Pampas movilizan este discurso de "lo verde" y "lo lindo" para oponerse a un conjunto de estrategias comerciales que podrían ser cubiertas por la etiqueta de
} 
consideran indisolubles de Mar de las Pampas y de un "estilo de vida" de las que éstas son condición necesaria y muchas veces suficiente. Aunque estos "vecinos" afirman no oponerse al "crecimiento" - lo cual en todo caso sería impopular e implausible en un contexto como el que acabamos de reconstruir - su adhesión aparece condicionada a que el mismo se dé de manera ordenada, regulado mediante una serie de disposiciones que limiten los usos legales y legítimos del espacio público y privado. Veremos asimismo que las dudas respecto de la efectividad de estos mecanismos los llevan a subrayar su voluntad firme de movilizarse en defensa de cualquier posible trasgresión, voluntad respaldada por un compromiso a la vez moral, estético y afectivo.

Una vez más, la nota periodística con la que comenzáramos nuestra caracterización de la historia reciente de Mar de las Pampas permite vislumbrar las principales tensiones suscitadas entre las dos posiciones, que habrán de ser recogidas por sucesivos textos periodísticos, incluyendo la cuestión de la previsibilidad y el ordenamiento:

"(...) el plano de Mar de las Pampas está subdividido de tal manera que el crecimiento inmobiliario se torna previsible y limitado. 'Las construcciones multifamiliares tienen su lugar y lo mismo las comerciales, de manera que el dueño de su casa sabe que en el lote vecino no levantarán un hotel o una cabaña', resaltó el (...) secretario de Planeamiento, Obras y Servicios Públicos de Villa Gesell.

las inquietudes y preocupaciones respecto de la efectividad de los mecanismos de control

El Código de Ordenamiento Urbano (...) aún no fue aprobado (...) y genera inquietud. 'Hay normas que no se están respetando, como los movimientos de arena y la tala de árboles', contó preocupada Marta Busteros, secretaria de la Sociedad de Fomento de Mar de las Pampas y vecina desde hace seis años (...)

las características excepcionales de Mar de las Pampas y el estilo de vida que las mismas configuran

(...) Ana Bianco, ex empleada textil que hace cuatro años vino de La Plata, compró una casa y la amplió para abrir Amorinda, un pequeño y cálido restaurante de pastas [declara] 'Aquí hay un bosque espectacular, playas vírgenes, música de pájaros y vecinos $y$ comerciantes que nos unimos en la lucha para que

"neoexclusivismo" y para promover un modelo alternativo que si bien puede ser entendido en algún sentido como "exclusivista" - o al menos "excluyente" - está menos informado por el mercado que por una suerte de meritocracia moral y estética autogestionada. Sin embargo, a lo largo del presente texto no nos ocuparemos de manera central de la cuestión de la construcción de Mar de las Pampas como localidad turística - lo que requeriría un trabajo específico de al menos la misma extensión que este - sino de manera contextualizada, en tanto este proceso aparezca imbricado con la movilización de los recursos y repertorios morales que constituyen el objeto del presente trabajo.

\section{el balneario crezca lindo' (...)}

y la firme voluntad de movilización en defensa de esos atributos:

Y como presidenta de la Asociación de Emprendedores Turísticos lanzó una advertencia: 'Seremos inflexibles con la zonificación vigente', dijo, convencida de que en un año o dos no habrá más lotes libres. 'Nos opondremos -dijo- a cualquier tipo de excepción'". El compromiso de los lugareños con su entorno es destacable (...)"10.

Las fuentes periodísticas locales también recogen con insistencia la percepción de un momento de quiebre que habrá de requerir una militancia vigilante y comprometida:

"(...) aquel verano 2003/2004 resultó un hervidero, un punto crítico y ardiente en la brutal explosión de crecimiento concentrada en apenas dos años, si tomamos como 'mojón' el verano 2001/2002 coincidente con el corralito y con la inauguración del primer paseo comercial. Para enero de 2004 se habían sumado [cuatro centros comerciales] y multitud de nuevos complejos hoteleros y gastronómicos (...) Podía añorarse, pero parecía inútil sentarse a renegar y así muchos tomaron la actitud de adaptarse a los nuevos tiempos y tratar, por todos los medios, de salvaguardar de la mejor forma posible aquel encanto que en diferentes momentos nos había traído hasta aquí. Decía Horacio Taranco en su extensa carta de febrero: '. .. permitir que [Mar de las Pampas] siga siendo lo que ha sido y cuidarla. Darle con claridad normas precisas, que regulen su crecimiento a partir de su esencia, que debe ser inamovible, porque fue lo que tanto atrajo desde sus primeros pininos'" (Trombetta 2010:25)

Aún a riesgo de precipitar el argumento, permítasenos adelantar que lo que en estas caracterizaciones periodísticas se anuncia como tensión implícita y amenaza latente habrá de transformarse en los años sucesivos en un conflicto abierto entre estos "vecinos", movilizados detrás del ideal de un Mar de las Pampas "natural", "tranquilo", "ecológico" y "hermoso" y una serie de actores - funcionarios municipales, emprendedores inmobiliarios y agentes de turismo - cuyos proyectos se articulan sobre un discurso de prosperidad y desarrollo, que busca la prolongación de esa curva ascendente que ha colocado a Mar de las Pampas tanto en la agenda periodística metropolitana como en el mapa de las opciones turísticas de los sectores medio-altos de la Argentina contemporánea (Bruno 2009, Furlán et alii 2010).

Ahora bien: si dejamos por un momento de lado las referencias esporádicas a estos conflictos en la prensa

\footnotetext{
10 Diario La Nación, "Sorprendente boom inmobiliario en Mar de las Pampas", 22 de septiembre de 2003, los subrayados son nuestros.
} 
de alcance nacional - apariciones que no son sino el emergente final de una serie de decisiones de agenda periodística que no estamos en condiciones de restituir aquí - y comenzamos a rastrear su trama en la escena local, veremos que el conflicto se presenta como continuo; como un marco en el que se juegan mes a mes - y a veces semana a semana - una serie de cuestiones que remiten en último término a la pregunta que parece enhebrar todos los debates: la pregunta identitaria. A medida que pasan los años, los residentes permanentes de Mar de las Pampas ${ }^{11}$ aparecen cada vez más dispuestos a embarcarse en consideraciones acerca de su identidad colectiva, siempre en diálogo con una serie de antagonistas - a veces específicos y personalizados, otras veces abstractos e innominados - que aparecen como permanente amenaza a un proyecto colectivo que, si bien encuentra antecedentes que preceden al boom inmobiliario y comercial reconstruido en los párrafos precedentes, ha comenzado a ser articulado de manera crecientemente explícita y detallada como respuesta a los desafíos presentados por el proyecto antagónico.

Así, cuestiones como: ¿qué es Mar de las Pampas y cómo somos sus habitantes? ¿Qué queremos llegar a ser y en qué no queremos convertirnos? ¿Quiénes intentan transformarnos en algo distinto de lo que somos y por qué? ¿Quiénes son nuestros aliados y quienes nuestros enemigos? y ¿Qué valores últimos justifican lo que queremos y lo que hacemos? aparecen con una regularidad impensada en las conversaciones entre y con sus residentes permanentes y ocupan un lugar central en la prensa local que constituye, en este sentido, una fuente invalorable para reconstruir la dinámica del debate, los repertorios movilizados, y las principales tensiones involucradas.

Sobre esta base, nuestro propósito será intentar reconstruir - a partir de un análisis basado primordialmente en fuentes periodísticas locales ${ }^{12}$ y sus repercusiones en la

\footnotetext{
11 Si bien por razones de extensión no podemos detenernos sobre este punto, quisiéramos señalar que aunque estos "residentes permanentes" de larga data sean quienes aparecen ocupando el lugar central en relación con los conflictos descriptos en el marco del presente trabajo, sus repertorios morales y estéticos y hasta cierto punto su activismo también pueden encontrarse en muchos de los residentes "de temporada" u ocasionales. Al contrario de lo que ciertos discursos - tanto nativos como eruditos - afirman acerca de la estacionalidad y su relación con el "sentido de pertenencia", veremos en breve que muchos visitantes de temporada comparten la identificación con Mar de las Pampas y su ethos, así como el compromiso moral con la causa de sus residentes permanentes, lo cual a su vez se muestra consistente con una serie de hallazgos más o menos recientes (Matarrita-Cascante, Stedman y Luloff 2010).

12 Más específicamente se trabajará sobre la base de El Chasqui de Mar de las Pampas, el único periódico local de circulación sostenida, cuyo primer número se remonta a octubre del año 2000 y que a partir de su número 6 - marzo de 2001 - ha aparecido con frecuencia mensual hasta el día de la fecha. El Chasqui... se distribuye de manera gratuita en varios puntos de Mar de las Pampas y del resto del partido de Villa Gesell, así como en un puñado de lugares de la Ciudad de Buenos Aires, y de algunas localidades del conurbano Sur y Norte. El Chasqui... es, en muchos sentidos, la obra material y el proyecto
}

prensa metropolitana ${ }^{13}$ la génesis y los contenidos de algunos de los repertorios morales a través de los cuáles los residentes permanentes de Mar de las Pampas de mayor arraigo justifican su pertenencia y la legitimidad de sus posiciones y acciones ${ }^{14}$.

La utilización central de fuentes escritas en general (y de materiales periodísticos en particular) en la construcción del argumento descansa sobre un supuesto básico: el de que estas fuentes, intervenciones públicas que - como veremos - procuran movilizar adhesiones y consensos lo más amplios posibles en el marco en una serie de polémicas en torno de cuestiones identitarias, recurrirán a los elementos de mayor saliencia de los repertorios implicados. Puesto de manera ligeramente distinta: a la hora de intentar argumentar un proyecto identitario en términos que intentan concitar un consenso más o menos generalizado, la retórica de los argumentos habrá de construirse por fuerza sobre la base de los tropos y los topoi que el enunciador supone relativamente compartidos, consensualmente valorados y mínimamente convincentes. En este sentido la presentación extensiva de citas periodísticas debe entenderse como un intento de mostrar las maneras recurrentes en que son movilizados los elementos de mayor currency de los repertorios morales y estéticos locales, elementos que los "emprendedores" de la "identidad marpampeana" consideran lo suficientemente persuasivos - incluso al punto de lo apodíctico - como para merecer ser incluidos a modo de recurso retórico convincente en argumentos destinados a públicos más o menos amplios.

Finalmente sobre esta base, y siguiendo un argumento de Mary Douglas (1986) procuraremos mostrar que la (re)construcción imaginaria ${ }^{15}$ de Mar de las Pampas que estos vecinos realizan, en el marco de una confrontación permanente con una serie de oponentes caracterizados en

intelectual de un solo hombre, Juan Pablo Trombetta, a quien agradecemos su generosidad al habernos cedido una colección casi completa del periódico.

${ }^{13}$ A título complementario, se hará un uso ancilario de de materiales obtenidos de la observación de conversaciones y la realización de entrevistas no estructuradas en el marco de nuestro trabajo de campo, allí donde las mismas aparezcan como prerrequisito para la comprensión - u ofrezcan elucidación adicional - de los recursos y repertorios movilizados en las fuentes escritas.

14 El siguiente texto forma parte de los proyectos de investigación "Fronteras Morales, Fronteras Sociales: Las Moralidades en el Proceso de Articulación de Identidades, Alteridades y Conflictos en Condiciones de Fragmentación Social" (UNSAM-CONICET) y "Moralidades, Fronteras Sociales y Acceso Diferencial a Recursos en Condiciones de Fragmentación Social" (UNSAMI) insertos en el programa "Naturalización y Legitimación de las Desigualdades Sociales en la Argentina Reciente" dirigido por el Dr. Alejandro Grimson en el IDAES/UNSAM. Agradezco a Jimena Ramírez Casas sus valiosos comentarios y sugerencias bibliográficas, y a mis informantes LM y MS su infinita paciencia para con mi pertinacia etnográfica.

15 Apenas hace falta señalar que "imaginaria" no implica "falsa" o "falaz", en la medida en que - como ha mostrado persuasivamente Benedict Anderson (2007) - toda comunidad es imaginada y que su carácter de tal no la hace menos eficaz (Grimson 2007, 2010). 
clave confrontativa (o incluso conspirativa) y concebidos como la encarnación de valores que se piensan antagónicos con su propio proyecto de largo plazo los constituye como comunidad relativamente cohesionada.

\section{Naturaleza y Calidad de Vida en la Génesis de "la Ciudad sin Prisa"}

Sabemos que a la hora de dar razones de sus posiciones, acciones y preferencias, los actores sociales no inventan ex nihilo los recursos ni las lógicas de sus argumentos, sino que se sirven de repertorios preexistentes a su alcance, de los cuáles pueden suponer con algún fundamento que cuentan con cierta legitimidad entre sus públicos actuales o potenciales (Austin 1957, Herzfeld 1982, 1988). Asimismo, ya Fredrik Barth (1976) señalaba la importancia de prestar debida atención al papel de los procesos de diferenciación y conflicto en la construcción de fronteras identitarias (cf. Grimson 2011). Siendo así, podemos esperar que nuestros informantes, los "vecinos históricos" de Mar de las Pampas, articulen sus respuestas a las preguntas implícitas por su identidad colectiva en confrontación con las respuestas alternativas de sus rivales, y recurriendo a una serie de metáforas, tropos y recursos retóricos que pueden ser considerados prestigiosos y persuasivos entre diversos públicos autoridades locales, turistas más o menos asiduos o la prensa de circulación nacional, entre otros - a quienes quisieran persuadir de la justicia de su causa.

Quizás el más extendido de estos repertorios y el es invocado con mayor frecuencia, es el de lo ecológico, entendido desde un conservacionismo que resalta el imperativo de minimizar el impacto del hombre y sus obras - si se nos permite forzar el conocido lexema evolucionista - sobre el "entorno" o la "naturaleza"16. Según sus formulaciones más familiares, Mar de las Pampas constituiría un "paraíso verde" configurado por la yuxtaposición de "el bosque" y "el mar", donde la arena, los árboles y los animales silvestres habrían convivido hasta hace muy poco en un relativo equilibrio con sus habitantes, equilibrio posibilitado por una presencia humana dispersa, con un mínimo impacto sobre el paisaje, y armónicamente integrada a él, tanto material como estéticamente.

Una de las formulaciones más explícitas y acabadas de los usos de este repertorio en la formulación de un proyecto colectivo puede encontrarse en un documento que lleva por título Mar de las Pampas: Su Espíritu y

\footnotetext{
16 "La ecología" y "lo ecológico" son, sin lugar a dudas, los temas que suscitan más atención por parte de la prensa local. El Chasqui de Mar de las Pampas publica ya en su número 4 (Febrero de 2001) una Introducción a la Reflexión Ecológica, y las contribuciones de biólogos, geólogos, oceanógrafos, paisajistas, urbanistas, agrónomos o simplemente "vecinos" con "conciencia ecológica" aparecen de manera constante, junto a descripciones "por entregas" de la flora y la fauna local, recomendaciones sobre reciclado, o referencias permanentes al "mundo indígena" en clave hiperreal (Ramos 1994).
}

Objetivos, presentado en ocasión de un debate en la Sociedad del Fomento local en relación con un proyecto de modificación al Código de Ordenamiento Urbano:

"Definición: Aldea Turística que tiene como principal recurso el atractivo de sus bellezas naturales y cuyos habitantes le imprimen un perfil claramente ecológico encauzado conforme los criterios de desarrollo sustentable y ecodesarrollo.

\section{Propuestas hacia un Desarrollo Armónico:}

Playa: Deberá continuar manteniendo su carácter virgen, no debiendo ser invadida ni deteriorada por la acción del hombre (...) No se permitirá la pesca (...) [ni] los deportes náuticos a motor [ni] el tránsito vehicular [ni] la amplificación de sonido de ningún tipo, ni la iluminación nocturna de la playa. (...) El sistema de duna y antiduna permanecerá intacto (...).

Bosque: La superficie construida (...) nunca podrá superar el 16\% de su extensión total (...). Se respetará en todo su desarrollo el [diseño] urbanístico y paisajista de sus fundadores (...). Se promoverá la redacción de un Código de Construcción que apunte al uso de materiales preferentemente naturales, no contaminantes (...) Se prohibe todo tipo de construcción en los espacios verdes (...) Se prohíbe la instalación de cualquier tipo de juegos electrónicos o eléctricos. La generación y desarrollo de fuentes alternativas de energía (solar) eólica) es compromiso de toda la comunidad, así como la eliminación definitiva de todo cableado aéreo. Se prohibe todo tipo de actividad contaminante sin excepción (...) Queda prohibida la tala de árboles, excepto por razones de seguridad, por tareas de mantenimiento de bosque y de construcción conforme a lo normado (...) El alumbrado público será el mínimo e imprescindible (...) siendo en todos los casos de baja luminosidad, con iluminación baja, indirecta y cálida. Se alentará la tracción a sangre exclusivamente como medio de transporte público interno (...) Las calles sólo podrán ser mejoradas mediante elementos provistos por la naturaleza en su estado original, pero nunca asfaltadas." 17.

Los diversos recursos ensamblados en este repertorio cuentan con genealogías fácilmente reconocibles. En primer lugar, y de modo central, el discurso de "lo verde" - leído como sinónimo de una naturaleza opuesta a los excesos de una vida urbana tóxica, amenazante y en cierto sentido inhumana - atraviesa buena parte de la seducción inmobiliaria dirigida a los sectores medios profesionales que consolidaron su ascenso social entre mediados y fines de la década de los 90', que en el área metropolitana de Buenos Aires (y en otras ciudades importantes del interior del país) suscitó la expansión de las urbanizaciones

\footnotetext{
17 Reproducido en El Chasqui de Mar de las Pampas, n 18, Mayo de 2002 .
} 
cerradas (Svampa 2001, Arizaga 2005) ${ }^{18}$ y que - como hemos visto - algunos autores reinscriben en el caso concreto de las localidades balnearias de la costa bonaerense como "neoexclusivismo" (Hernández 2009a, 2009b). Y sin duda alguna, parte de su eficacia persuasiva debe también mucho a la sedimentación en la longue durée de una oposición bien conocida que les da sustento: la antítesis que opone "el campo" a "la ciudad" como el "vicio" a la "virtud" - y cuyas sucesivas transformaciones históricas para el caso de Inglaterra ha reconstruido magistralmente Raymond Williams (2001).

Mas este sintagma metonímico de "lo verde" no se agota en consideraciones arquitectónico-paisajísticas. Más allá de que la parte central del conflicto acerca de la "identidad" de Mar de las Pampas gire en torno del modelo de desarrollo turístico-inmobiliario y su impacto concreto sobre una naturaleza "preexistente"19 " "lo verde" predica al mismo tiempo de un determinado "estilo de vida" (Maciel y Krischke Leitão 2010). La naturaleza no sólo debe ser protegida y conservada sobre la base de un imperativo categórico: debe ser conservada porque de ello depende una calidad de vida particular, que buena parte del mundo urbano habría perdido a mano de las siempre voraces "fuerzas del progreso" y de la especulación sin freno.

Ahora bien: si a principios de la década los llamados a la "vida verde" se presentan y argumentan en una forma débilmente articulada que apela tanto a vagas filosofías naturistas como a un hippismo epigonal (Webster 1975) y que resuenan con ciertas formas de consumo "virtuoso" que comienzan a interpelar a ciertas fracciones de los sectores medios urbanos contemporáneos (Wortman 2003), en los últimos años han ganado en articulación y sustento a través de su inscripción en un repertorio transnacional de creciente exposición mediática: el movimiento slow (Honoré 2006, Meyer y Knox 2006). A partir del hallazgo de este novedoso y atractivo repertorio de identificación, a mediados de la presente década, Mar de las Pampas comenzará a ser (re)presentada como la "Ciudad sin Prisa" y como refugio del frenesí de una vida

\footnotetext{
${ }^{18}$ Apenas hace falta señalar que este recurso no es exclusivo del escenario nacional: el mismo suele acompañar a los procesos de suburbanización en diversas latitudes (cf. Low 2004).

19 Si bien siguiendo la epistemología naturalista habitual de la modernidad (Descola 2006) la "naturaleza" es presentada por nuestros informantes como teniendo precedencia cronológica, lógica y moral sobre una presencia humana ulterior, adventicia y potencialmente depredatoria, cabe destacar que la "naturaleza" en cuestión es resultado de un proceso antropogénico de construcción del paisaje que ha transformado - y simplificado - de manera radical los ecosistemas costeros (Mar Azul S.A. 2009). Si bien, como veremos en breve, este proceso de transformación - común a las localidades de la denominada "Costa Verde Argentina" (Guías Regionales Argentinas 2001) - no sólo es conocido sino es incluso celebrado por los habitantes de estas localidades como parte de las epopeyas fundacionales (cf. infra), sus efectos son elididos en las reconstrucciones de una naturaleza prístina y amenazada, lo cual muestra una vez más, como señalara Mary Douglas (1986) que las instituciones configuran formas específicas del recuerdo y del olvido.
}

urbana contemporánea caracterizada por una velocidad que no dejaría tiempo a la introspección, el ocio creativo y el disfrute. Con entusiasmo de converso, sus habitantes embanderados bajo esta nueva causa comenzarán a hacer profesión pública de su repudio a ciertos principios centrales de la modernidad avanzada: la eficiencia, la velocidad, la conexión permanente, la centralidad del mercado y el consumo (Virilio 1993), que comenzarán a ser imputados con una carga moralmente negativa a sus oponentes. Y aunque la identificación con el movimiento slow no agregue demasiados elementos a los repertorios que los habitantes de Mar de las Pampas presentaban como característicos de su singularidad moral y estética, lo cierto es que los articula de una manera novedosa que multiplica su eficacia y permite construir una serie de discursos que estimulan la imaginación de esos actores sociales movilizados en torno del discurso de "lo verde" (Svampa 2001, Arizaga 2005), que comienzan a identificarse con "la causa" de los pobladores locales en una alianza que desestabiliza al menos una parte de los argumentos de los emprendedores de mediana y gran escala. Puesto que si es en efecto la singularidad de Mar de las Pampas en cuanto "ciudad slow"20 la que lo transforma en un potencial polo de atractivo turístico, queda claro que desdibujar esa oferta no tiene mayor sentido, incluso desde la más estricta racionalidad economicista. Como lo enuncia una carta del Correo de Lectores de El Chasqui:

"[Mar de las Pampas] tiene su propia alma. Y se la quieren maquillar con eufemismos de confort (...) ¿qué infraestructura? ¿Qué confort? ¿No entienden que eso está en otro lugar? ¿No entienden que eso está en Buenos Aires y [la gente] viene a Mar de las Pampas buscando que hasta el celular no agarre señal? ¿No entienden que los chicos de Buenos Aires nunca vieron un sapo? ¿Qué el animal más conocido es un Pikachu' ${ }^{21}$ ? ¿Qué el árbol más cercano que les tocó ver es el de la vereda? ¿Qué a los ejecutivos tapados de laburo de la ciudad y con un stress galopante les encanta caminar en patas por las calles de arena, trepar un médano para clavar la sombrilla donde se les cante y hacer pis en el mar? (...) Entendemos que es importante crecer, progresar, pero salgamos un poco del formato. No se crece ni se

\footnotetext{
20 Técnicamente, deberíamos escribir "candidata a ciudad slow", puesto que más allá de la identificación exitosa de la localidad como la ciudad slow de la Argentina, tanto hacia dentro como extramuros, Mar de las Pampas no ha logrado la muy buscada certificación internacional de "slow city". Como además es sumamente dudoso que lo logre, dados ciertos factores como la presencia de centros comerciales con franquicias nacionales e internacionales, restaurantes con comida de producción industrial y la ausencia de una actividad productiva local que permita el autosustento (entre muchas otras) el tema de la certificación, luego de ocupar un lugar notorio en el debate durante los años 2006 y 2007 (ver, por ejemplo “Mar de las Pampas: la ciudad que será slow" en Página/12 del 22 de Enero de 2006), ha desaparecido súbita y silenciosamente de la escena. Las condiciones de certificación pueden encontrarse en http://www.cittaslow.net

21 Se trata de un personaje de la serie japonesa Pokemón, muy popular a principios de la década.
} 
progresa de una única manera..."22.

Una vez más, podemos encontrar evidencia del empuje persuasivo de este nuevo repertorio ante públicos más amplios en algunos de estos argumentos que son recogidos en tono elegíaco y prácticamente verbatim por los medios periodísticos metropolitanos de circulación nacional. A título de ejemplo podemos mostrar la siguiente nota del diario La Nación, la cual mediante el recurso de la enumeración hace hincapié en una serie de características que definen - por presencia o por ausencia - a Mar de las Pampas como ciudad slow, a la vez antítesis y antídoto de la estresante vida urbana:

"Una aldea donde no hay otro afán que veranear sin prisa

\section{Allí hasta los celulares quedan olvidados: no suenan porque no hay antenas}

(...) En este balneario no hay supermercados, ni lavaderos, ni postes de luz en las calles. Tampoco hay discotecas, ni "fichines", ni estaciones de servicio. No hay asfalto, ni carteles publicitarios. Y en la playa sólo existe un parador.

Nada importa, porque los servicios que buscan los turistas son otros, tales como muchos espacios verdes, erradicación de la contaminación sonora y visual, playas libres de estructuras $y$, fundamentalmente, tranquilidad. Mucha tranquilidad.

"Lo que buscamos es descansar. Desenchufarnos de todo y, como dicen los carteles, vivir sin prisa. Bah, en nuestro caso, el lema correcto sería veranear sin prisa, porque lamentablemente no vivimos acá", contó (...) Isabel Vázquez (...) que eligió esta localidad para disfrutar de sus vacaciones por segundo año consecutivo.

Entre los turistas del lugar predominan parejas jóvenes con hijos pequeños que consultados sobre por qué eligen Mar de las Pampas para veranear, responden, sin excepción alguna, que lo hacen "por su tranquilidad". Sucede que esta villa (...) se distingue del resto de los balnearios de la costa atlántica por cultivar un estilo desacelerado, donde el apuro es inconcebible o, mejor dicho, impracticable, porque todo tiende a imponer un ritmo de vida lento.

Sus calles, por ejemplo, no sólo son de arena, sino que, además, el zigzagueo de las arterias principales y el sinnúmero de culs de sac, (calles sin salida) reduce el impacto vehicular: (...) La velocidad máxima permitida es de $30 \mathrm{~km}$ por hora ${ }^{23}$.

\footnotetext{
22 El Chasqui de Mar de las Pampas, carta de Gabriela Carozzi y Jorge Ibañez, n³3, Agosto de 2003.

23 Cabe señalar que los carteles viales que indican las máximas permitidas - en general grabados sobre madera barnizada en un estilo "rús-
}

(...) El lema "vivir sin prisa" surgió dos años atrás, de la Asociación de Emprendedores Turísticos (AET) local, que decidió ponerle firma a un proyecto que llevaba años de trabajo. "Encontramos que el camino que estábamos siguiendo ya lo habían transitado y plasmado por escrito otros, en otras partes del mundo, que hablaban del concepto de slow city. Así fue como decidimos promover, para Mar de las Pampas, la idea de vivir sin prisa", explicó (...) [el] presidente de AET. En tal sentido (...) otro integrante de la asociación, señaló: "El punto es olvidarse de la correría y disfrutar más y mejor del tiempo. Acá, mucha gente llega, estaciona el auto, y no lo vuelve a sacar hasta que se va".

La finalidad es preservar el lugar: "La gente que nos visita viene a buscar esto, que consiste en la no interferencia entre la naturaleza y el hombre. No hay iluminación en las calles, para que se puedan ver las estrellas y la luna. Estas son las cosas que conforman nuestro atractivo turístico", sostuvo Straffurini. "24

Al mismo tiempo, en la medida en que los habitantes movilizados de Mar de las Pampas consiguen capturar la imaginación de los cronistas y corresponsales metropolitanos - y a fortiori de turistas asiduos o potenciales - a través de consignas "ecologistas" que resuenan con fuerza ante ciertos auditorios provenientes de sectores medio-altos ${ }^{25}$, acumulan respaldos para su relato identitario, de manera tal que su narrativa de "comunidad virtuosa amenazada por las voraces fuerzas de la modernidad y el mercado" gana a la vez en visibilidad, legitimidad y eficacia y crea una serie de espacios propicios a potenciales alianzas entre los "vecinos preocupados" y estos turistas "que busca[ría]n lo mismo" que ellos:

En Mar de las Pampas hay mar de fondo entre vecinos $y$ shoppings ${ }^{26}$

\footnotetext{
tico" o "campestre" - van acompañados de una indicación descriptiva: "Estamos caminando".

24 Diario La Nación, "Una aldea donde no hay otro afán que veranear sin prisa", 17 de febrero de 2007, los subrayados son nuestros. Una vez más, el artículo periodístico presentado no es sino un ejemplo particularmente estilizado extraído de un conjunto de textos similares que se multiplican en la prensa metropolitana ( $q v$. "Un elogio de la lentitud" en Página/12, suplemento M/2 del 25 de enero de 2007, "Mar de las Pampas: un refugio de bosque, naturaleza y mar" en La Nación del 26 de Enero de 2008 o "La aldea que quiere crecer, pero sin prisa" en La Nación del 12 de Enero de 2009.

25 Si bien no hemos conseguido aún estadísticas que permitan respaldar nuestras impresiones iniciales, surge de nuestros relevamientos exploratorios que un número considerable de los veraneantes que eligen Mar de las Pampas como destino recurrente de veraneo son precisamente académicos, mediadores culturales y profesionales pertenecientes a esas fracciones de los sectores medios con altas credenciales educativas en los cuáles el movimiento slow ha encontrado la mayoría de sus adherentes en Europa y los Estados Unidos (Mayer y Knox 2006).

26 Así como la "aldea" funcionaba en la nota precedente, como sinécdoque de una Gemeineschaft bucólica, "el shopping [center]" en
} 
Los habitantes de Mar de las Pampas se debaten entre fomentar una invasión turística que favorezca a los comerciantes o mantener la exclusividad del sosiego.

\section{(...)}

Mar de las Pampas, (...) sigue alimentando el sueño de consolidarse como Slow City, la primera Ciudad Lenta del continente. (...) a pesar de la aprobación de un Código de Edificación que restringe aún más el total de metros cuadrados permitidos para las nuevas viviendas o locales comerciales, es notorio el crecimiento de la ciudad que, por suerte para los defensores del proyecto original, todavía sigue perdida en el bosque. Claro que son varios los que temen que se convierta en una nueva Carilón $27 .(.$.

Turistas y residentes permanentes aparecen unidos en torno de valores y voluntades unánimes:

"El problema no es el turista, que cuando hace su elección busca en Mar de las Pampas la tranquilidad de la que carecen otros lugares. El problema está en nosotros mismos", asegura [el presidente saliente de la Asociación de Emprendedores Turísticos] Straforini, en alusión a la población fija de Mar de las Pampas.

Esto creció y creció mal. Tenemos que discutir mucho, para cambiar el rumbo si no queremos que esto deje de ser el lugar tranquilo que queremos y que buscan los turistas", dice (...) otro de los "históricos" (...)"

El problema parecería ser, según estos "emprendedores morales" que no todos los comerciantes locales parecen entender la existencia o el alcance de este acuerdo:

"El proyecto que alientan (...) es el de una ciudad sin autos circulando por sus calles, que siguen sin ser asfaltadas. (...) La idea no cuenta con el apoyo decidido de los dueños de locales comerciales a los cuales "les encanta que la puerta de sus negocios se llenen de autos con gente ávida de comprar, como en las grandes ciudades", se queja una vez más el "histórico", que insiste en su oposición a que Mar de las Pampas "se convierta en un shopping". La tendencia, considerada negativa por la mayoría de los consultados, dio lugar a una dura controversia con uno de los nuevos centros comerciales (...) que provocó movilizaciones de sectores de la población y reclamos de la Sociedad de Fomento de Mar de las Pampas. Las quejas se debieron a que los propietarios del centro comercial invadieron con la construcción espacios verdes comunes a turistas y pobladores estables (...)".

Una vez más, el episodio aparece inscripto en el marco de

la Argentina de principios de siglo, funcionaba como indicador metonímico de "los 90" y de la censura moral hacia un consumismo desenfrenado e irrestricto incubado al calor del neoliberalismo y la Ley de Convertibilidad (cf. nota 4, supra).

27 “En Mar de las Pampas hay mar de fondo entre vecinos y shoppings", Página/12, 30 de enero de 2007. una vigilancia permanente, imprescindible para la defensa de la "ciudad lenta":

"La lucha por mantener la ciudad lenta es permanente. Mazzoni recuerda que el año pasado hubo una gran actividad para impedir la instalación (...) de una antena para facilitar el uso de celulares (...). La tecnología que agobia en las grandes urbes es mala palabra en Mar de las Pampas. "El instalador quedó rodeado cuando estaba en las alturas, listo para terminar su trabajo. No hubo violencia, no es nuestro estilo, pero le dijimos que si ponía la antena, no bajaba." El empleado de la empresa telefónica hizo consultas, por su celular. Luego de algunos cabildeos, recibió la contraorden y se fue sin instalar la antena. Como premio, lo invitaron a una comida con todos los chiches y la cosa terminó en paz. La firma igual instaló la antena, a ruta abierta, fuera de los límites de la ciudad (...)"

Y de la necesidad de poner límites precisos al crecimiento:

"Para los vecinos 'sensibles' de Mar de las Pampas el tema es mucho más que una anécdota de un verano 'exitoso' en lo económico. 'Lo que corre peligro es la ciudad que queremos y que tiene, como tope, una población estable de dos mil personas y cuando mucho, siete mil visitantes', afirma el 'histórico' quejoso (...)." 28

\section{Vigilar y Movilizar(se)}

La verosimilitud y la fuerza persuasiva de este relato de "comunidad amenazada" obtienen ulterior respaldo de la evocación de la "trágica historia" de dos localidades vecinas que, a partir de inicios promisorios a la vez que paralelos con los de la que nos ocupa, habrían visto truncado un desarrollo potencialmente virtuoso a manos del canto de sirena de las fuerzas de un "progreso" desencadenado ya por la falta de previsión (y del correlativo establecimiento de límites), ya por la voracidad

\footnotetext{
28 Tanto sus biógrafos como el mismo Gesell hacen constante hincapié en su vida austera y su filosofía de vida naturista. Sus respuestas a una entrevista realizada sobre el final de su vida ofrecen un resumen relativamente estilizado de esta presentación:
}

\begin{abstract}
"¿Qué tipo de vida lleva Ud.?
Yo pienso que una persona que no se ha echado a perder por un exceso de civilización, debe buscar la naturaleza. Soy naturista. Duermo mucho. No fumo. Casi no tomo alcohol (...) No voy a bailes. No trasnocho. Antes de que vaya la gente me voy a bañar al mar, muy temprano (...)". (Guías Regionales Argentinas 2001:87)
\end{abstract}

A partir de las reconstrucciones llevadas a cabo por sus biógrafos - y en especial por su hija Rosemarie (Gesell 1983) - y con cierto grado de imprudencia analítica, puede argumentarse que el naturismo del Viejo Gesell tiene raíces tanto en su socialización en el marco de una familia de Mitteleuropa de fines del siglo XIX y comienzos del XX - de la cual habría adquirido la desconfianza por la Zivilization y sus artificios (Elias 2000) - como de su contacto con un individualismo libertario heredero de Emerson y Thoreau durante una prolongada estadía en los Estados Unidos a comienzos de su vida adulta, que habría de marcarlo profundamente. 
del mercado y sus campeones.

El primero de estos casos implica a Villa Gesell, la localidad cabecera del partido, con cuya historia la totalidad de los vecinos de Mar de las Pampas están familiarizados en abundancia (sobre todo cuando muchos de ellos provienen de allí). Las habituales versiones hagiográficas de la historia local - un género particular e idiosincrásico que hemos tenido ocasión de analizar en otra parte (Noel 2011, qvv. Oviedo 2008:16ss) - la reconstruyen como la epopeya unipersonal de un visionario: Carlos Idaho Gesell - el "Viejo Gesell" - cabal representante de un voluntarismo faústico moderno (Berman 1991), naturista ${ }^{29}$ y autodidacta (Sierra 1969, Masor 1995) y ecologista avant la lettre (Gesell 1983, Saccomano 1994), que a partir de su genio y su tesón y venciendo dificultades insuperables habría logrado construir un primer "paraíso verde" a orillas del mar, un remanso de tranquilidad y de armonía entre el hombre y la naturaleza construido a espaldas de y en repudio a una civilización corrompida y corruptora ${ }^{30}$. Este ideario fundacional se prolongaría - entre fines de la década del 60' y comienzos de la del $70^{\prime}$ - en la eflorescencia fugaz pero intensa del hippismo (Saccomano 1994, Oviedo 1995) que habría de reformular el libertarianismo y el naturismo del Fundador en clave de emancipación espiritual y rebelión explícita e irreverente contra los convencionalismos de la sociedad urbana y moderna (Hall y Jefferson 2002). Sin embargo, a partir de mediados de la década del 70' se habría producido un quiebre (Saccomano 1994:133, Oviedo 2005, Noel 2011), de manera tal que el proyecto inicial - que recurría para la construcción de su singularidad identitaria a recursos análogos a los que los vecinos de Mar de las Pampas movilizan en la defensa de la suya ${ }^{31}$ - habría quedado

\footnotetext{
${ }^{29}$ Cabe detenerse aquí en los efectos de esa reconstrucción retrospectiva que Bourdieu (1997) denominara "la ilusión biográfica". Si bien sobre finales de su vida, tanto Gesell como sus biógrafos plantean la fundación de "la Villa" en una clave estratégica de largo plazo que involucra componentes si no ecologistas al menos conservacionistas (Guías Regionales Argentinas 2001:86, Saccomano 1994), las reconstrucciones que preceden a la consolidación de esta narrativa históricobiográfica (Sierra 1969, Masor 1995) nos muestran una dosis considerable de vacilación y una sucesión de proyectos cuya filiación con un "ecologismo" que no puede ser más que anacrónico es cuando menos dudosa: desde vender arena para construcción, a un criadero de pollos o de cerdos, pasando por plantaciones específicamente destinadas a producir madera para cunas y cochecitos de bebé manufacturados por la entonces pujante empresa familiar de muebles para niños, Casa Gesell. Significativamente, en las versiones más recientes esta historia comienza a ser reescrita una vez más y - en aras de una consistencia "ecologista" - el proyecto del aserradero es presentado como "una excusa" que el Viejo Gesell habría pergeñado para "tranquilizar a su familia" (Ortiz 2010:73-74).

30 En muchos casos, hay más allí que un simple paralelismo: en los relatos de sus pobladores más antiguos, aparece en ocasiones la historia de una "huida" de una "Villa" que pierde su fisonomía naturista y libertaria, para intentar "comenzar de cero" en Mar de las Pampas y llevar adelante una vez más - esta vez de manera exitosa - lo que Gesell quiso y pudo ser, pero lamentablemente no consiguió ser (Oviedo 2005:27, 143)

31 "La Villa” es el etnónimo que los pobladores utilizan habitualmente para referirse a su ciudad. Apenas hace falta aclarar que está
}

trunco. La desviación se habría producido cuando "la Villa" 32 cede al canto de sirena de la prosperidad económica y da la espalda a la filosofía minimalista de su fundador para embarcarse en un modelo de turismo masivo (Oviedo 1995:26) que fomenta la construcción desenfrenada y no planificada de la mano de una especulación inmobiliaria que promueve (y consigue) "leyes permisivas" que "desvirtúan" el proyecto original (Ortiz 2010:112-115, 162ss). Así es que Villa Gesell crece de modo espectacular, transformándose en uno de los destinos turísticos más populares de la Argentina (Ortiz 2010), pero al tiempo que gana el mundo, "pierde su alma" (Oviedo 1995), pasando a ser lo que hoy es: "una ciudad", con todos los vicios que al menos desde Herder en adelante se imputan como consecuencia y sinónimo de la vida urbana ${ }^{33}$ y de una Zivilisation artificial, inhumana y decadente . $^{34}$.

Las lecciones de esta historia, leída en clave de apólogo, resultan más que obvias. Si un proyecto tan promisorio y con tanto empuje, llevado adelante por la voluntad indoblegable de un hombre a todas luces excepcional, pudo ser desviado - incluso en vida de éste y ante sus propios ojos y su explícita desaprobación - y transformado en su döppelganger por una combinación entre la falta

desprovisto de todas las connotaciones estigmatizantes asociadas al término "villa" en el imaginario de los sectores medios metropolitanos de la Argentina.

32 Como hemos señalado en otra parte (Noel 2010), estos relatos de la decadencia reproducen obsesivamente una narrativa del paso de la Gemeineschaft a la Gesellschaft.

33 Si bien hay cierta unanimidad en la caracterización de este proceso como un "proyecto frustrado", coexisten diversos géneros de reconstrucciones, desde las de inspiración más sociológica (que constituyen una minoría, qv. Brunet 2009) hasta las abiertamente conspirativas, como la caracterización que hace Ortiz (2010:174ss, 184) de "un viejo león puesto de rodillas por los chacales [de la especulación inmobiliaria]", que le habrían arrebatado su proyecto revolucionario para transformarlo "en un negocio más".

34 La movilización se despliega de manera constante y simultáneamente por varias vías desde la acción vigilante de la Sociedad de Fomento de Mar de las Pampas (SoFo) respecto de la política municipal y su difusión a través de El Chasqui..., su órgano oficioso con el objeto de asistir masivamente a las sesiones del Concejo Deliberante que los implican, la realización de Seminarios sobre temas como La Participación Ciudadana en la Defensa del Ambiente (El Chasqui de Mar de las Pampas, $\mathrm{n}^{\circ}$ 43, Junio de 2004) o Qué Futuro queremos para Mar de las Pampas (El Chasqui de Mar de las Pampas, n 101, Abril de 2009), la denuncia de irregularidades o ilegalidades en relación con la zonificación, los permisos de construcción o la apropiación y destrucción del espacio público (El Chasqui de Mar de las Pampas, n 83, Octubre de 2007) hasta ciertas formas acción directa, como la constitución de "brigadas voluntarias de vecinos" (El Chasqui de Mar de las Pampas, $\mathrm{n}^{\circ}$ 21, Agosto de 2000) o de "resistencia pasiva" como el bloqueo a la acción de maquinarias en construcciones no autorizadas (El Chasqui de Mar de las Pampas, n 9, Agosto de 2001), la instalación de antenas de telefonía celular (El Chasqui de Mar de las Pampas, n 53, Abril de 2005) o la realización de un rally (El Chasqui de Mar de las Pampas, $n^{\circ}$ 92, Julio de 2008). Una vez más, considerando la contemporaneidad de los hechos que aquí relatamos con esos "tiempos extraordinarios" inmediatamente posteriores a la crisis del 2001 (Svampa 2004), no puede descartarse que muchas de estas modalidades de acción colectiva resultaran inspiradas por un clima de movilización tan generalizado como pluriforme. 
de planificación y una voracidad económica cortoplacista, es menester permanecer vigilante y evitar por todos los medios posibles que la historia se repita. Máxime, cuando hubo momentos de la historia reciente - como en los inicios del boom - en los que había razones para creer que un destino paralelo se cernía sobre el nuevo paraíso:

"La irrupción del corralito en aquellos dias [de fines de 2001] habría de provocar un quiebre, ya que tras la devaluación, una ola de inversores apostó por Mar de las Pampas y sobrevendría el boom de crecimiento, no paulatino ni armónico. Durante algunas temporadas no podría precisarse si se trataba de un lugar en construcción o en ruinas. Sin dudas un antes y un después, ya que terminaba el ciclo según el cual llegaban a este bosque familias con sus pequeños proyectos gastronómicos $u$ hoteleros, para predominar emprendimientos de mayor envergadura, con inversores que no se radican, en la mayor parte de los casos, en Mar de las Pampas (...)" (Trombetta 2010:12).

A los ojos de los "vecinos" de Mar de las Pampas esto implica en principio dos corolarios, a los que ya nos hemos referido en passant. En primer lugar, la promoción y defensa de dispositivos legales que impidan formalmente una expansión edilicia descontrolada: de ahí la letanía permanente de normas, regulaciones, códigos de edificación y disposiciones que hemos visto en las notas ya citadas, y con las que buena parte de sus habitantes están tan familiarizados como un predicador con la Escritura. Asimismo, en la medida en que la efectividad de estos dispositivos es cuando menos dudosa - en especial frente al potencial poder corruptor del dinero es menester realizar una vigilancia continua tanto sobre los agentes encargados de su ejecución y cumplimiento como sobre aquellos que querrían violarlos en beneficio propio o ajeno, y una movilización contundente y masiva allí donde aparezcan indicios de una violación real o potencial. Y la organización de esta movilización debe ser colectiva, dado que - como muestra la historia de Gesell - ni siquiera el más excepcional de los mortales puede resistir por sí solo a las fuerzas destructoras de la codicia. Así es que se explica la existencia de ese estado de deliberación y movilización permanente al que hiciéramos referencia en nuestros párrafos iniciales, y que tiene como objetivo principal mantener el proceso de crecimiento dentro de los parámetros morales y estéticos considerados aceptables por sus residentes permanentes (y a fortiori por sus aliados entre los turistas más o menos habituales) $)^{35}$.

Mas este destino de masificación turística y expansión inmobiliaria cortoplacista y predatoria que habría puesto fin al sueño naturista y libertario del Viejo Gesell no es la única amenaza potencial que se cierne sobre el segundo "paraíso verde". Veíamos ya en una de las citas

\footnotetext{
35 La Nación, "Sorprendente boom inmobiliario en Mar de las Pampas", 22 de septiembre de 2003
}

periodísticas precedentes que se señalaba la importancia de que Mar de las Pampas no se convirtiera en "una nueva Cariló", y es este balneario vecino, en el partido adyacente de Pinamar (a unos $20 \mathrm{~km}$ de distancia) el que irrumpe en los relatos de nuestros informantes y en las fuentes consultadas como un segundo analogado, más próximo tanto en el tiempo como en la imaginación. Resulta sorprendente, sin embargo, que si bien la comparación se remonta a más de una década, la misma ha invertido su signo de manera muy reciente: en las primeras menciones periodísticas de Mar de las Pampas en la prensa metropolitana casi siempre aparece en clave de elogio o de promesa - se habla de "la nueva Cariló", "el pequeño Cariló" 36 o "la versión en miniatura de Cariló" "37 y los paralelos discurren por los ejes de "el bosque", "la tranquilidad" y "el verde". Sin embargo, la analogía habilita una segunda clave de lectura que, si bien rara vez aparece subrayada en estas primeras comparaciones, será la que concite la atención de esos inversores y grandes emprendedores comerciales e inmobiliarios que nuestros informantes consideran perjudiciales: la implicación de que Mar de las Pampas eventualmente se transforme (como Cariló) en uno de los balnearios más exclusivos y de mayor valor agregado de la costa atlántica bonaerense ${ }^{38}$ (Hernández 2009a, 2009b, Ortiz 2010:185ss).

Y así, a medida que esta lectura comience a traducirse en proyectos, obras y franquicias y que Mar de las Pampas comience a crecer y a poblarse de emprendimientos hoteleros, gastronómicos y comerciales dirigidos a ese segmento de consumidores diferenciados que la jerga del marketing denomina "ABC1", las comparaciones elogiosas comenzarán a transformarse en voces de alarma $^{38}$. Y aunque superficialmente la mayor parte de estas preocupaciones se expresen casi en los mismos términos en que lo hacían las críticas al crecimiento de Villa Gesell - la inquietud por un desborde edilicio que amenaza el entorno natural y la tranquilidad correlativa - queda claro que no se ha producido en Cariló nada que pueda compararse con la urbanización masiva de "la Villa" y que los "excesos" - como sus mismos críticos lo reconocen - se circunscriben a un centro comercial que no ocupa más de una decena de hectáreas. Un análisis más cuidadoso revela que la diferenciación moviliza un criterio menos urbanístico que de clase, y que refiere a una proliferación exhibicionista leída como síntoma de un espíritu "comercial" o "consumista" llevado al extremo de la mano del consumo conspicuo y de la "obsesión por las marcas", y encarnado con frecuencia en la doble

\footnotetext{
36 La Nación, "Mar de las Pampas atrae con bosques y playas solitarias", 27 de enero de 2001.

37 Clarín, "Mar de las Pampas sigue creciendo y ya casi no quedan terrenos en venta", 30 de enero de 2008.

38 Las expresiones más remotas de esta inquietud pueden encontrarse en la prensa local en fecha tan temprana como Mayo de 2001, cuando comienza a construirse el primero de los centros comerciales de Mar de las Pampas, Sendas del Encuentro (El Chasqui de Mar de las Pampas, $\left.n^{\circ} 6\right)$, y volverán a repetirse con la construcción de grandes emprendimientos hoteleros (El Chasqui de Mar de las Pampas, $\mathrm{n}^{\circ 37}$ ).
} 
sinécdoque de "el cuatriciclo y la [camioneta] 4x4" (Ortiz 2010:185, 199):

\section{"(...) quienes habitan Mar de las Pampas reniegan de que} se los considere una hermana menor de Cariló. 'Cariló está etiquetado, empapelado de marcas. Todos están pendientes de lo que hace el otro. El que busca unas vacaciones para figurar se va para allá, el que busca un sello de bajo perfil viene acá', opina Vázquez. Mar de las Pampas diseñó un concepto de exclusividad propio que no pasa sólo por los precios. No existen las mansiones majestuosas, pero sobran las casas que se levantan en culs de sac para evitar las aglomeraciones de tránsito. (...) Aquí manda el 'menos por más'. "39

"Creo que lo peor que podría pasarnos... bah, lo peor no, lo peor sería que asfaltaran todo y llenaran todo de edificios como en Gesell... pero una de las peores cosas sería que [Mar de las Pampas] se transformara en un lugar careta como Cariló, donde la gente vive pendiente de qué te pusiste... de qué auto tenés. Vos ves [a] la gente como va a la playa y parece que fuera a un casorio [casamiento] o a una fiesta de quince... quieras o no, eso es otra fuente de stress, además de que me parece una actitud de cuarta" (Adriana, 29 años, residente desde hace 14 años)

"Qué se yo... una de las mejores cosas de acá es que no se juzga a nadie por lo que tiene o no tiene... y aunque hay gente que por ahí la levanta con pala, no te lo anda refregando por la cara... por ahí ni te enterás. Me parece que a veces la cosa se entiende al revés... o sea esto no es para cualquiera, pero no porque tengas, no sé, una $4 \times 4$ sino porque el espíritu de Mar de las Pampas no es para cualquiera... exige una cierta forma de ser... y usar ropa de marca es como que no es... no pasa por ahí esa forma de ser, pasa más por algo de acá [una actitud mental] (Mario, 34 años, residente desde hace 17 años)"

Como se ve, nuestros informantes trazan una oposición neta entre un exclusivismo elitist $a^{40}$ construido sobre la base de un consumo no sólo conspicuo sino abiertamente ostentoso y una exclusividad virtuosa basada en esa moral minimalista y conservacionista que ya hemos encontrado, hostil al consumismo ${ }^{41}$.

A su vez, el repudio de esa identificación que en principio

\footnotetext{
39 Clarín, "Mar de las Pampas sigue creciendo y ya casi no quedan terrenos en venta", 30 de enero de 2008.

40 En más de un sentido, la reconstrucción analítica del "neoexclusivismo" al que hemos hecho referencia (Hernández 2009a, 2009b) reproduce de cerca - y de manera harto sospechosa - varios de los estereotipos de impugnación moral que los habitantes y turistas habituales de Mar de la Pampas arrojan sobre sus vecinos de Cariló, lo que puede sugerir una insuficiente distancia analítica o una necesidad de mayor trabajo empírico a los efectos de superar la transcripción literal y en clave analítica de las representaciones nativas de censura.

41 Cabe subrayar que esta misma oposición opera en los procesos de distinción que los habitantes de Villa Gesell construyen respecto de su partido vecino, Pinamar (Oviedo 1995:10, Ortiz 2010:2).
}

aparecía como digna de elogio se amalgama en la afinidad solidaria entre dos ethos de clase: por un lado, un repudio de la artificialidad y la artificiosidad - y una profesión correlativa de la importancia de lo "sencillo" y lo "auténtico" - que puede encontrarse con mayor frecuencia entre los primeros pobladores de Mar de las Pampas, con un pasado como trabajadores manuales, cuentapropistas o artesanos (Trombetta 2005:18ss, cf. Bourdieu 2006) y por otro una crítica a la desmesura y a la ostentación desde una posición que elogia la sobriedad y el justo medio, más típica de los profesionales y emprendedores que se han instalado en los últimos años, o de quienes que la frecuentan como turistas (cf. Tevik 2006, Adamovsky 2009) ${ }^{42}$.

\section{Estética y Temperamento en una Localidad Balnearia}

Aún así, cuando dejamos atrás el registro periodístico para pasar a la información recogida en entrevistas e historias de vida, encontramos que esta diferencia moral es constantemente inscripta en clave psicológica, o incluso caracterológica. Si decíamos antes que lo que está en juego en el "ecologismo" de los residentes permanentes de Mar de las Pampas no es sólo un conservacionismo que busca "defender la naturaleza de los excesos del hombre", sino la protección de un estilo de vida que se traduce en calidad de vida, muchos de nuestros informantes dan un paso más allá y anclan este "estilo de vida" en un "temperamento" que postula una homología entre el paisaje local y sus residentes. Según estas reconstrucciones - deudoras de un determinismo geográfico sumamente frecuente en la literatura local (Saccomano 1994, Masor 1995, Ortiz 2010:28) - la relación entre Mar de las Pampas - con frecuencia reducido a la sinécdoque de "el bosque" 43 - y sus habitantes, va más allá del bienestar o incluso de la identificación subjetiva, alcanzando una inscripción en su cuerpo y su temperamento (en una suerte de versión nativa del habitus bourdiano en clave geográfica). Es esta inscripción lo que diferencia al auténtico poblador, el residente permanente, del turista, incluso del más entusiasta:

"... acá es como que el lugar te cambia. Yo me acuerdo cuando llegué, empecé a ver que la gente de acá tenía... no sé cómo explicarte... como un aire, una actitud... es como que ves a alguien y sin que nadie te diga nada

\footnotetext{
42 Aún así, persisten los intentos por reinscribir el minimalismo conservacionista de los "vecinos" de Mar de las Pampas en un modelo de marketing elitista y diferenciado dirigido al "segmento $A B C 1$ ", como lo muestra Mar de las Pampas MAG, una publicación local cuyo formato ("48 páginas a todo color impresa en papel fotográfico de excelente calidad"), target ("Está orientada al consumidor final de gran poder adquisitivo $\left.A B C 1 / C 2^{\prime \prime}\right)$ y esquema de distribución - Capital Federal, Zona Norte del Conurbano Bonaerense y varios de los countries de mayor renombre - intentan interpelar explícitamente a ese sector (qv. http://mardelaspampasmag.com.ar).

43 También la genealogía de "el bosque" como sinécdoque del paisaje de Mar de las Pampas puede rastrearse hasta su antecedente inmediato, Villa Gesell (Masor 1995, Oviedo 2005).
} 
ya sabés si es de acá o [si] no es, por como camina, como se para, como mira... el modo [lento] de hablar... (Fernando, 37 años, residente desde hace 6 años)"

Los relatos que predican esta homología admiten por lo general dos variantes, no siempre excluyentes. La primera opera sobre la base de la vocación, en la cual el temperamento en cuestión preexiste hasta cierto punto al contacto con "el bosque", pero sólo es revelado en su plenitud en ese momento de claridad en el que se produce el encuentro en el que el narrador encuentra su auténtico y predestinado lugar en el mundo. Siendo así, resulta cualquier cosa menos sorprendente que estos relatos utilicen en abundancia los tropos del enamoramiento y del "flechazo":

"... si bien andábamos buscando un lugar, no habíamos pensado en Mar de las Pampas... y no habíamos pensado porque no lo conocíamos [ríe]... Pero fue llegar y es como que todo se acomodó de golpe, es como que dije 'Este es mi lugar en el mundo. Quiero pasar el resto de mi vida acá'". (Adriana, 29 años, residente desde hace 14 años)

"... Vi los pinos y ichau! El flechazo. Fue amor a primera vista. Es como cuando conocés a la mujer de tu vida. No querés saber nada más. No querés que te presenten a nadie más, ni que te hablen de nadie más. Decís: es esta. Con esta me caso. Esta es la madre de mis hijos. No sabés por qué, pero lo sabés... es como que te hace un 'clic' y todo te cierra". (Nahuel, 34 años, residente desde hace 4 años)

La segunda variante comienza con una relativa indiferencia, un compromiso tibio o incluso cierto escepticismo para poner de relieve un proceso de conversión ${ }^{44}$ en el cual el "hombre viejo" - al que se la atribuyen todos los vicios de la vida urbana a los que ya hemos hecho referencia: el stress, el "vivir a mil", diversas enfermedades orgánicas o psicológicas. - es regenerado a través del efecto redentor del paisaje y transformado en un hombre pleno, física, intelectual y moralmente saludable.

"Tenías que ver lo que era yo cuando me vine: parecía mi bisabuelo... Tenía el colesterol por las nubes, vivía de mal humor, saltaba por cualquier boludez... el 'estresazo', ¿viste? Vos estás allá y ni te das cuenta... es como que te acostumbrás... y te juro que si no me venía, se venía el bobazo [infarto]... ¿sabés a cuántos ví de mi edad?

\footnotetext{
44 En algunos casos extremos, la conversión suscitada con el contacto con el paisaje genera un sentimiento de indignidad que desencadena una suerte de ascesis que precede a la identificación plena, como lo muestra el caso de Mariano Aldazábal, un artesano del cuero que señala "Hará veinte años que tomé contacto por primera vez con este bosque, me enamoré; en realidad buscaba que el bosque me aceptara a mí y en esa ocasión me pareció un exceso, no sabía si lo merecía" y que desarrollará una aproximación progresiva hacia ese "bosque" estableciéndose primero como pequeño agricultor y artesano en el tercer cordón del conurbano (Trombetta 2005:20).
}

Caen como moscas... y me vine acá y chau... es otra cosa, es como que el aire te limpia, te pone diez puntos... estoy hecho un pibe. Te digo que ni anteojos uso ya... Al principio la gente me decía 'ya vas a ver, ya te va a pasar', y yo ni bola les daba... o sea, es obvio que estás más tranquilo acá... pero de ahí a que te cambie la vida... y bué, les tuve que dar la razón". (Arturo, 52 años, residente desde hace 14 años)

Los contenidos de este temperamento que es revelado en su plenitud - en la versión de la vocación - o suscitado por el contacto con el paisaje - en la versión de la conversión - abarcan un conjunto de virtudes y disposiciones que se predican como consustanciales al "estilo de vida" de Mar de las Pampas ${ }^{45}$. En primer lugar la sencillez y la austeridad, un cierto "amor por lo simple" 46 o incluso por "lo rústico": como hemos visto vivir en Mar de las Pampas implica algunas privaciones desde el punto de vista de un urbanita acomodado, pero son precisamente estas privaciones las que a la vez hacen posible y dan testimonio de una relación privilegiada con el mundo "natural" sin las prótesis adormecedoras de una Zivilisation decadente ${ }^{47}$.

En segundo lugar, y de la mano del "silencio" (Mar Azul S.A. 2009:24), una cierta actitud "filosófica" o "contemplativa" (Oviedo 2005:19) que estimularía la introspección y el diálogo interno para los cuales el "el ruido y el frenesí de la ciudad" no dejan tiempo, alentando una autorrealización en la cual "la persona se encuentra consigo misma" (Mar Azul S.A. 2009:24) y "el hombre es redimensionado como eje de la vida" (Trombetta 2005:25). Esa introspección, a su vez, sometería a los espíritus a una dura prueba de autoconocimiento "que no todos están en condiciones de pasar". Su resultado sería la autenticidad que resulta de un conocimiento de sí transparente, de un "oír la propia voz"48.

\section{"Acá es como que no tenés donde esconderte... no tenés}

\footnotetext{
45 Una vez más, la inmensa mayoría de estos rasgos no sólo no son novedosos, sino que han sido predicados casi en los mismos términos - y en muchas ocasiones lo siguen siendo - de su inmediato antecedente: Villa Gesell (Oviedo 1995).

46 Este rasgo encuentra un eco más o menos cercano en el atributo que los residentes de Villa Gesell señalan como sinónimo de su ethos y del de su ciudad: la informalidad (Saccomano 1994:132).

47 Este amor por "lo rústico" ha generado - y sigue generando - algunas tensiones similares a las que Maristella Svampa (2001) presenta en la relación entre "viejos" y "nuevos" residentes de los countries, en las que éstos demandan una serie de "comodidades" consideradas innecesarias (o incluso contraproducentes) por aquéllos. Sobre todo en tiempos recientes, esta oposición aparece subrayada en reconstrucciones retrospectivas de los inicios de Mar de las Pampas, cuando "no había nada" y sin embargo "se estaba mejor que ahora".

48 En este sentido, "el primer invierno", es decir los primeros meses fuera de temporada que un residente pasa en la localidad y caracterizado por "condiciones crudas", "nostalgia", "frío", "humedad", "melancolía" o "incertidumbre", que enfrentan a los pobladores a sí mismos en una desnudez que no le permite ocultarse en el ruido de "los turistas" y "la temporada" son presentados como el auténtico rito de paso que definen la posibilidad de ser "aceptado" por la localidad y su comunidad (Oviedo 2005:23, Trombetta 2005:11).
} 
el ruido, el gentío... acá sos vos, el bosque y vos... y no es para cualquiera, porque es como que te enfrentás a vos mismo, al vos auténtico... y más vale que te guste lo que ves... si no... si no ... no sé cómo hacés". (Arturo, 52 años, residente desde hace 14 años)

En tercer lugar, el arraigo, un amor incondicional por la localidad y su paisaje, que se traduce en un compromiso militante $e$ insobornable: del mismo modo que uno defendería con su vida a su familia o a su pareja y jamás se dejaría sobornar o corromper en ese empeño, el amor "al bosque" debe traducirse en una lucha inclaudicable por su preservación, especialmente ante intereses espurios que no quieren, no pueden o no saben reconocer la excepcionalidad de lo que tienen ante sus ojos:

"Elias Pitluk, fomentista y dueño de Aike Malen, explica que conviene 'saber diferenciar entre colonizadores ${ }^{49}$, los que llegamos aquí en busca de un cambio de vida, y conquistadores: aquellos inversores que ni siquiera vienen a ver qué es lo que están levantando'"50.

"(...) Como quiera que fuese, a todos nos subyugaron el bosque, el mar, los pájaros, la paz. Es, pues, nuestro ineludible deber colaborar para que el crecimiento sea lo menos doloroso posible, para que un interés personal no se anteponga a los de la comunidad que pretendemos fundar $(. . .)^{\prime \prime} 51$

"... es como con tus hijos... si alguien amenaza a tus hijos, ponéle... vos saltás. No pensás, no decís 'Uh, por ahi hay que hacer esto o lo otro'. Saltás y te la jugás, porque son tus hijos, son parte de vos... son vos... en cierto sentido. $Y$ esto es igual. Tenemos algo que nadie tiene... nadie tiene lo que nosotros tenemos... y conservarlo así, como está, con esta belleza... lo vale todo ". (Iris, 56 años, residente hace 14 años)

Como corolario de estas virtudes surge además un fuerte sentido de comunidad, en la cual los residentes se transforman en "vecinos" y "recuperan" una solidaridad que se expresa en modos de relación atribuidos al pasado y que la vida urbana habría arrasado, y en el cual se busca que "cada día el 'nos' reemplace el 'yo' y el destino común al triunfo individual"52.

Aún cuando los contenidos de esta homología psicológicamente imputada sean de naturaleza moral, su fundamento es presentado específicamente como estético. Las virtudes que han enamorado o incluso transformado

\footnotetext{
49 La metáfora del "colonizador" es sumamente frecuente en los pobladores de mayor arraigo, y suele operar por referencia al analogado principal del "pionero" (Trombetta 2005:19, Noel 2011).

50 "Nosotros defendemos el silencio" en Clarín, 27 de Noviembre de 2006.

51 El Chasqui de Mar de las Pampas, 10, Septiembre de 2001. Este texto corresponde al primer editorial aparecido en el periódico.

52 El Chasqui de Mar de las Pampas, 12, Noviembre de 2001.
}

de manera radical a los residentes permanentes de Mar de las Pampas nacen fundamentalmente de "la belleza", "la majestad", "la tranquilidad" o "el silencio" del "bosque". Serían precisamente esta belleza y esta tranquilidad las principales fuentes del temperamento contemplativo de sus habitantes (Oviedo 2005:62-63) y la fuente permanente tanto de su virtud como de su compromiso, por lo cual es este el tesoro que debe ser protegido con más entusiasmo.

Ahora bien: las afinidades postuladas entre paisaje y temperamento como las que acabamos de ilustrar están lejos de ser inusuales. Como lo ha mostrado un número de trabajos recientes provenientes del campo de la geografía, los procesos de identificación con el paisaje y con el medio - refractados o no a través del prisma del "estilo de vida" - suelen tener un fuerte impacto sobre el sentido de pertenencia así como sobre lo que la literatura anglosajona suele denominar el "sense of place" (Matarrita-Cascante et alii 2010, Brehm 2007), particularmente cuando se trata de lugares con un notorio atractivo turístico fundado en ese mismo paisaje y pobladores de establecimiento reciente. También se encuentran instancias de imputación de afinidad electiva entre determinadas clases de paisaje y determinadas clases de personas así como la idea de que ciertos rasgos del primero funcionan como una suerte de "prueba" o "sacrificio" que sólo algunos habrán de superar con éxito.

Por su parte, la cuestión de los fundamentos estéticos del compromiso moral también encuentra antecedentes en algunos procesos de suburbanización y gentrificación ${ }^{53}$ (Svampa 2001, Low 2004), en lo cuáles - como lo ha mostrado el trabajo reciente de Setha Low (2009) nociones de "lo lindo" o "lo bello" son movilizadas constantemente como manera de proponer criterios legítimos de exclusión - o al menos más difíciles de impugnar que otros más "políticamente incorrectos" como raza, clase u origen étnico o migratorio ${ }^{54}$. A la luz

\footnotetext{
53 Aún cuando desde el punto de vista de la caracterización "neoexclusivista" ya mencionada (cf. Notas 9 y 41, supra) las transformaciones edilicias de Mar de las Pampas sean con frecuencia asimiladas a procesos de "gentrificación", faltan muchos de los indicadores considerados típicos en estos procesos (Herzer 2008), tales como el aumento desproporcionado del nivel educativo de los residentes, el aumento de las tasas de desalojo, la disminución del número de propietarios que adeudan impuestos inmobiliarios, la disminución del tamaño de los hogares, el aumento de los alquileres o el cierre de negocios que atendían clientes con bajos consumos y su reemplazo por negocios que apuntan a consumidores con ingresos más altos. Lo que falta en el caso de Mar de las Pampas es el proceso de "renovación" o "reconversión" de zonas marginales o degradadas, típico de los procesos de gentrificación, aún cuando puedan existir algunos de sus rasgos como el aumento relativo de los precios de venta de locales comerciales, el aumento de inversiones privadas en el barrio durante un periodo dado, el incremento de la tasa de permisos de construcción en el área, o el aumento de alquileres comerciales.

54 Como lo ha señalado Baumgartner (1988) incluso suburbanitas aislados y entusiastas practicantes de un "minimalismo moral" que busca evitar el conflicto a cualquier precio desencadenan mecanismos de control social ante lo que perciben como infracciones "estéticas" a su entorno.
} 
de estas consideraciones podemos ver cómo y hasta qué punto la exclusividad virtuosa de los habitantes de Mar de las Pampas a la que nos hemos referido en la sección precedente consigue diferenciarse con éxito en términos de legitimidad moral del exclusivismo elitista de sus homólogos de Cariló. Nuestros informantes alegan, sin doblez, que en Mar de las Pampas "no se discrimina a nadie" y que ni el poder adquisitivo, ni el origen de clase constituyen óbice para ser incluido como miembro de pleno derecho en la comunidad local. Pero al mismo tiempo, nunca dejan de señalar que es la localidad misma, a través de su paisaje, y más concretamente de cierta actitud contemplativa hacia la belleza que de él emana - una belleza "sencilla", "natural", en el doble sentido de arraigada en la naturaleza y desprovista de artificios y afeites - la que "revela" quien porta el tau de los elegidos y puede, por tanto, aspirar a ser reconocido como legítimo partícipe del "estilo de vida" local y de su defensa colectiva. Como hemos intentado mostrar a lo largo de este texto, los residentes permanentes de Mar de las Pampas tienen muy en claro qué es lo bueno y lo verdadero, porque saben qué es lo bello... et unum convertuntur.

\section{Conclusiones: La Confrontación en la Génesis de una Identidad Colectiva}

Como señalábamos en los párrafos finales de nuestra Introducción, uno de los rasgos más sobresalientes entre los residentes permanentes de Mar de las Pampas es su alto grado de reflexividad identitaria: todos ellos parecen, todo el tiempo, y a la menor excusa, estar dispuestos a preguntarse (y a responder) acerca de los atributos que definen su identidad colectiva. Hemos intentado delinear también los contornos de un proceso de creciente articulación de estos atributos en un repertorio altamente consensuado - moral en su contenido, estético en sus fundamentos - que se desencadena a partir de ese boom inmobiliario post-crisis que marca "un antes y un después" en la historia de la localidad y que habrá de encontrar su formulación más acabada en una convergencia con el movimiento slow. A su vez, ese repertorio moral prescribe un compromiso colectivo y militante basado en el amor por el paisaje y en la contemplación de su belleza - y $a$ fortiori - en la inscripción duradera de ese lazo estético en clave psicológico-caracterológica.

Ahora bien, como lo ha mostrado Mary Douglas (1996, 1986:65ss), las "teorías conspirativas" ocupan un lugar central en la génesis del lazo social en pequeñas comunidades. Según el argumento de la autora, la transformación de un "grupo latente" (Olson, citado en Douglas 1986:45ss) en un grupo más o menos consolidado implica la existencia de un mecanismo que permita el establecimiento de una frontera relativamente duradera que opere como barrera de salida y vuelva poco atractiva para los miembros de ese grupo latente la opción de defeccionar. Y en los procesos de establecimiento de una frontera de esta clase, ocupa un lugar central "una creencia compartida en una conspiración maligna" que suscita la posibilidad de movilizar "acusaciones mutuas de traición a los principios fundamentales de la sociedad" tanto hacia aquellos que amenazarían con retirarse como a potenciales free-riders - o al menos hacia aquellos miembros cuyo compromiso es juzgado insuficiente (Douglas 1986:87).

A la luz del argumento presentado a lo largo de nuestro texto, esperamos haber dejado razonablemente claro que un proceso de estas características habría tenido - o mejor aún, estaría teniendo lugar - en Mar de las Pampas durante la última década. La existencia y la naturaleza específica de la conspiración involucrada - según nuestros informantes y nuestras fuentes - está a la vista:

"La cosa acá está muy clara: hay un par de tipos... bah, más de un par... que quieren hacer su negocio... aunque eso implique destruir todo lo que hace de Mar de las Pampas un lugar hermoso e inigualable... A ellos no les importa. Les importa el billete... y todos tiran para ese lado, negociantes [hombres de negocios] políticos... todos. Si nosotros no tiramos también todos para el mismo lado, nos pasan por arriba, porque mal que nos pese, ellos también tienen un proyecto, un proyecto de mierda, pero que lo tienen, lo tienen... Son como la langosta... pasan, te asfaltan, construyen, dejan tierra arrasada y empiezan de nuevo con el bosque de al lado..." (Beatriz, 42 años, reside desde hace 15 años)

Sus agentes son los "conquistadores", las fuerzas de un "progreso mal entendido" y voraz que amenazan con desencadenar sobre el nuevo "paraíso verde" un Kali Yuga edilicio, inmobiliario y consumista que ya arrasó con paraísos anteriores. Ante la amenaza de esta profanación no se puede ser neutral, de modo tal que la tibieza o la falta de compromiso militante pueden y aún deben leerse como sinónimo de complicidad o de "haberse vendido" a las fuerzas de la destrucción (como lo muestran las numerosas catilinarias que se multiplican en la prensa local, dirigidas funcionarios insuficientemente comprometidos con la causa de la conservación). Asimismo, la lucha permanente por la defensa de Mar de las Pampas y su especificidad exige una delimitación cada vez más precisa de qué es lo que se está defendiendo, con lo cual los contenidos morales y los fundamentos estéticos de ese repertorio identitario ganan en definición y articulación, adquiriendo un carácter progresivamente apodíctico. No sólo la pertenencia no es una simple cuestión de residencia o de afinidad, sino que una identificación legítima - en el sentido de pacíficamente aceptada por aquellos a quienes interpela: los restantes pobladores que se movilizan colectivamente en su defensa - se reconoce por su inscripción profunda en el temperamento, en las emociones y en el cuerpo, en ese amor militante que asimila a Mar de las Pampas a los afectos más íntimos, incuestionables y cercanos. Ser 
Guardián de este Paraíso es condición necesaria para merecerlo.

Buenos Aires, 20 de Abril de 2011

\section{Bibliografía}

Adamovsky, E. 2009. Historia de la Clase Media Argentina, Buenos Aires: Planeta.

Anderson, B. 2007. Comunidades Imaginadas. Reflexiones sobre el Origen y la Difusión del Nacionalismo, Buenos Aires: FCE.

Arizaga, C. 2005. El Mito de Comunidad en la Sociedad Mundializada, Buenos Aires: El Cielo por Asalto.

Austin, J. 1957. "A Plea for Excuses" en Proceedings of the Aristotelian Society, 57, 1956-7:15.

Barth, F. 1976. Los Grupos Étnicos y sus Fronteras: la Organización Social de las Diferencias Culturales, México: FCE

Baumgartner, M. 1988. The Moral Order of a Suburb, Oxford: OUP.

Berman, M. 1991. Todo lo Sólido se Desvanece en el Aire, México: Siglo XXI.

Brehm, J. 2007. "Community Attachment: The Complexity and Consequence of the Natural Environment Facet", Human Ecology, 35(4): 477-488.

Brunet, F. 2009. Paradojas Geselinas. Información Política, Económica y Social, Mar del Plata: Editorial Martín.

Bourdieu, P. 1997. Razones Prácticas. Sobre la Teoría de la Acción, Barcelona: Anagrama.

Bourdieu, P. 2006. La Distinción. Criterios y Bases Sociales del Gusto, Madrid: Taurus.

Descola, P. 2006. "Más allá de la Naturaleza y la Cultura" en Etnografías Contemporáneas, I: 93-114.

Douglas, Mary 1986. Cómo Piensan las Instituciones, Madrid: Alianza.

Elias, N. 2000. The Civilizing Process, Oxford: Blackwell.

Furlan, A., F. Hernández y J. Ordoqui 2010 “El Desarrollo Territorial en los Asentamientos Turísticos Balnearios del Litoral Marítimo de la Provincia de Buenos Aires, Argentina. Un Abordaje Multidimensional para el Análisis de Problemáticas Concretas", trabajo presentado en el X ${ }^{e r}$ Coloquio Internacional de Geocrítica, Mar del Plata,
Argentina.

Gesell, R. 1983. Carlos Idaho Gesell: Su Vida, edición de autor.

Grimson, A. 2002. "La Nación después del Deconstructivismo. La Experiencia Argentina y sus Fantasmas" en Sociedad, 20/2, Verano 2002.

Grimson, A. 2007. "Introducción" en Pasiones Nacionales. Política y Cultura entre Argentina y Brasil, Buenos Aires: Edhasa.

Grimson, A. 2010. Los Límites de la Cultura, Buenos Aires: Siglo XXI.

Guías Regionales Argentinas 2001. Villa Gesell. La Costa Verde Argentina, Buenos Aires: Alfonsina.

Hall, S. y T. Jefferson 2002. [1975] Resistance through Rituals. Youth Subcultures in post-War Britain, London: Routledge.

Hernández, F. 2009a. "Nuevas Espacialidades y Paisaje Turístico. El Neoexclusivismo en el Litoral Marítimo Bonaerense, Argentina" en Nadir 1.2.

Hernández, F. 2009b. "Cultura de la playa: Sociabilización, ocio y territorio en los balnearios de la costa atlántica bonaerense, Argentina" en Argos (26)51:48-66.

Herzer, H. (Org.) 2008. Con el Corazón Mirando al Sur: Transformaciones en el sur de la Ciudad de Buenos Aires, Buenos Aires: Espacio Editorial.

Herzfeld, M. 1982. "The Etymology of Excuses: Aspects of Rhetorical Performance in Greece", American Ethnologist, 9(4): 644-663

Herzfeld, M. 1988. “Embarrassment as Pride: Narrative Resourcefulness and Strategies of Normativity among Cretan Animal-Thieves", Anthropological Linguistics, 30(3-4):319-344

Honoré, C. 2006. Elogio de la Lentitud, Buenos Aires: del Nuevo Extremo.

Lees, L. y D. Ley 2008. "Introduction to Special Issue on Gentrification and Public Policy" en Urban Studies 45(12):2379-2384

Low, S. 2004. Behind the Gates: Life, Security, and the Pursuit of Happiness in Fortress America, London: Routledge.

Low, S. 2009. "Maintaining Whiteness: The Fear of Others and Whiteness" in Transforming Anthropology, 172:79-92. 
Maciel, M. E. y D. Krischke Leitão 2010. "Apresentação" en Horizontes Antropológicos. Antropologia e Estilos de Vida, 16(33):1-4.

Mar Azul S.A. 2009. Mar de las Pampas, Anticipo del Paraíso, Buenos Aires: Mar Azul S.A.

Masor, O. 1995. La Historia de Villa Gesell, Villa Gesell: Gesatel.

Matarrita-Cascante, David, R. Stedman y A. Luloff 2010. "Permanent and Seasonal Residents' Community Attachment in Natural Amenity-Rich Areas. Exploring the Contribution of Landscape-Related Factors", Environment and Behavior, 42(2):197-220.

Mayer, Heike y Paul L. Knox 2006. "Slow Cities: Sustainable Places in a Fast World" en Journal of Urban Affairs, 28, 4:321-334.

Noel, G. 2010. "Credenciales Impecables. Algunos Repertorios Culturales y sus Usos en la Delimitación de una Comunidad Moral", ponencia presentada en las Vlas Jornadas de Investigación en Antropología Social, Universidad de Buenos Aires, 3 al 6 de Agosto de 2010.

Noel, G. 2011. "'Pioneros': La Literatura, el Documental Televisivo y su Rol en la Construcción de un Repertorio Identitario", en preparación.

Oviedo, J. 1995. El Alma Perdida de Gesell. Ensayo sobre los Años Sesenta y Parte de los Setenta en la Villa, edición de autor.

Oviedo, J. 2008. No Todo lo que Reluce es Oro Primera Parte, edición de autor.

Ramos, A. 1994. "The Hyperreal Indian" in Critique of Anthropology, 142:153-171.
Saccomano, G. 1994. El Viejo Gesell, Buenos Aires: Alfonsina.

Semán, P. 2006. “Historia, Best-sellers y Política" en Bajo Continuo. Exploraciones Descentradas sobre Cultura Popular y Masiva, Buenos Aires: Gorla.

Svampa, M. 2001. Los Que Ganaron: La Vida en los Countries y Barrios Cerrados, Buenos Aires: Biblos.

Svampa, M. 2004. "Relaciones Peligrosas. Sobre clases medias, gobierno peronista y movimientos piqueteros" en El Rodaballo, X:15 Invierno 2004.

Tevik, J. 2006. Porteñologics. El Significado del Gusto y la Moralidad en la Clase Media Profesional Porteña, Buenos Aires: Antropofagia.

Trombetta, J. 2005. El Chasqui de Mar de las Pampas. Tomo I 2000-2005., Mar de las Pampas: El Chasqui.

Trombetta, J. 2010. El Chasqui de Mar de las Pampas. Diez Años en Mar de las Pampas, Mar de las Pampas: El Chasqui.

Virilio, P. 1993. El Arte del Motor. Aceleración y Realidad Virtual, Buenos Aires: Manantial.

Webster, C. 1975. "Communes: A Thematic Tipology" en Hall, Stuart y Tony Jefferson 2002. [1975] Resistance through Rituals. Youth Subcultures in post-War Britain, London: Routledge.

Williams, Raymond 2001. [1973] El Campo y la Ciudad, Buenos Aires: Paidós.

Wortman, Ana (Comp.) 2003 Pensar las Clases Medias. Consumos Culturales y Estilos de Vida Urbanos en la Argentina de los Noventa, Buenos Aires: La Crujía. 